\title{
Material Weakening of Slip Zone Soils Induced by Water Level Fluctuation in the Ancient Landslides of Three Gorges Reservoir
}

\author{
Yu-Yong Jiao, ${ }^{1}$ Liang Song, ${ }^{1}$ Hui-Ming Tang, ${ }^{2}$ and Yun-An $\mathrm{Li}^{2}$ \\ ${ }^{1}$ State Key Laboratory of Geomechanics and Geotechnical Engineering, Institute of Rock and Soil Mechanics, \\ Chinese Academy of Sciences, Wuhan 430071, China \\ ${ }^{2}$ Engineering Faculty, China University of Geosciences, Wuhan 430074, China \\ Correspondence should be addressed to Yu-Yong Jiao; yyjiao@whrsm.ac.cn
}

Received 24 January 2014; Revised 12 July 2014; Accepted 14 July 2014; Published 4 August 2014

Academic Editor: Pavel Lejcek

Copyright (C) 2014 Yu-Yong Jiao et al. This is an open access article distributed under the Creative Commons Attribution License, which permits unrestricted use, distribution, and reproduction in any medium, provided the original work is properly cited.

\begin{abstract}
This experimental study investigated the effect of repeated wetting and drying on the reduction of slip zone soils taken from the Huangtupo landslide in the Three Gorges Reservoir, China. The variation process of the physical property and substance composition of the slip zone soils under the wetting-drying cycles was studied through liquid and plastic limit test and X-ray diffraction test. The results indicate that (1) the shearing strength of the slip zone soil dramatically decreased after one wettingdrying cycle and then gradually decreased until reaching a relatively stable state at the fourth cycle; (2) the plasticity index of the slip zone soil varied with increasing number of cycles and a variation process opposite to that of the strength value was observed; and (3) the clay mineral content in the slip zone soil increased and the calcite and quartz contents relatively decreased with increasing number of cycles. The variations in the plasticity index of the slip zone soil, as well as the increase in its clay mineral content, play important roles in the strength reduction. The results of this study provide a foundation for revealing the deformation and damage mechanism of landslides in reservoir banks.
\end{abstract}

\section{Introduction}

The Three Gorges Reservoir, located between the upstream of Yangtze River's Sandouping, Yichang City, and Jiangjin, Chongqing City, is $690 \mathrm{~km}$ long. The reservoir's geographic coordinates are $106^{\circ} 30^{\prime}-111^{\circ} 02^{\prime}$ in east longitude and $29^{\circ} 30^{\prime}-$ $31^{\circ} 20^{\prime}$ in northern latitude. The Three Gorges project is currently the world's largest water-control project with $5,300 \mathrm{~km}$ of reservoir banks in total. So far, more than 2,500 largescale landslides have been found in the reservoir area, among which over 100 landslides cover more than $1 \times 10^{6} \mathrm{~m}^{3}$ area and 14 have $1 \times 10^{7} \mathrm{~m}^{3}$ area [1]. China had managed nearly 600 landslides through the geological disaster prevention in the second and third construction stage to guarantee the normal operation of the Three Gorges Reservoir, as well as the security of the lives and properties of people living in the reservoir area. According to incomplete statistics, more than 1,190 large and small landslides within the influencing range of $175 \mathrm{~m}$ water level of the Three Gorges Reservoir have various deformation distributions. After impounding, the water level in the reservoir area had increased by tens to almost hundreds of meters.

For the purposes of flood control and power generation, the reservoir's water level under normal operation is lowered to the lowest level of $145 \mathrm{~m}$ during flood seasons, say June to September. However, the water level is increased to the highest level $(175 \mathrm{~m})$ through impounding after the flood season (October) to satisfy the demands of electricity production. Consequently, the water level of the reservoir produces a periodic variation of approximately $30 \mathrm{~m}$ (from $145 \mathrm{~m}$ to $175 \mathrm{~m}$ ). Such frequent water level variation is significantly greater than the water level variation caused by natural conditions $[2,3]$. Water level variation can soften the rock-soil mass of the reservoir bank and cause variations in groundwater table, which consequently lowers the shear strength of the rock-soil mass, leads to slaking of the rock-soil mass, and resultantly influences the stability of landslides [4-6]. Therefore, such changeable hydrogeological condition can cause landslides in the Three Gorges Reservoir. Numerous landslides have occurred since the first impounding in June 2003 because of the impact of water level variation. Landslides aggravate and 
revive the deformation of many ancient landslides, such as the Qianjiangping and Baishuihe landslides, among others. In particular, the Huangtupo landslide in Badong County had, respectively, experienced two movements in June and November 1995 prior to the establishment of the Three Gorges Dam. After reservoir impounding, the bottom of the Huangtupo landslide drowned completely and 20,000 residents around the riverside had to migrate [7].

The water level fluctuation and rainfall are two important factors that influence the stability of landslides in reservoir banks. Many scholars have recently investigated the landslides in the Three Gorges Reservoir with consideration of water level variation and obtained fruitful results. Wang et al. [8] applied the three-dimensional limit equilibrium method to analyze the stability of landslides under different water levels and believed that, after reservoir impounding, the hydrostatic pressure is beneficial for the stability of landslides. Jiang et al. [9] investigated the stability of landslides during the lowering of water level through the coupled fluidsolid theory. They concluded that the lowering of water level increases the osmotic pressure and effective stress in landslide mass and consequently leads to landslides. Based on the hydrological continuity equation, Hong and Wan [10] introduced a prediction method and a computational model for groundwater table fluctuation, taking the impact of rainfall into account. Considering artificial rainfall and reservoir water level variation, Jia et al. [11] and Yan et al. [12] established a large landslide test platform to study the features of permeability, deformation, and failure of landslides. Besides the methodologies mentioned above, different numerical approaches have been developed to simulate the landslide process $[13,14]$. In general, previous studies on the effects of water level variation and rainfall on slope stability can be summarized into the following two aspects: studies on the permeability character of landslide mass and studies on landslide stability under the effect of reservoir water. Although the slip zone has the weakest strength and is a critical factor in controlling the landslide stability, efforts on the strength of the slip zone soils, particularly those on the variations in slip zone soil strength under the periodic fluctuation of reservoir water level, are rare.

Taking the Huangtupo landslide in the Three Gorges Reservoir as an example, this study experimentally investigates the reduction law of the strength of original slip zone soil under wetting-drying cycles. Besides, this study discusses the micromechanism of the wetting-drying cyclic effect by using the liquid and plastic limit and X-ray diffraction (XRD) tests.

\section{Engineering Geological Conditions of the Huangtupo Landslide}

The Huangtupo landslide, located in the Badong County, Hubei Province, south bank of Yangtze River, is one of the largest and most complicated landslides in the Three Gorges Reservoir. The Huangtupo landslide has upper, middle, and bottom surface slopes of $40^{\circ}, 15^{\circ}-20^{\circ}$, and $30^{\circ}-35^{\circ}$, respectively. Moreover, its front edge, drowned by water, has an elevation of approximately $50 \mathrm{~m}$ to $70 \mathrm{~m}$, and its trailing edge has an elevation of approximately $600 \mathrm{~m}$. The Huangtupo landslide covers an area of $1,358 \mathrm{~km}^{2}$ and has a volume of $6934.1 \times 10^{4} \mathrm{~m}^{3}$. Most surfaces of the landslide are covered by loose debris with average thickness of $40 \mathrm{~m}$ to $50 \mathrm{~m}$. The bedrock stratum mainly comprises the second and third segments of the Badong formation in the Triassic system. The second section of the Badong Group is located in the upper part of the landslide and its lithology alternates between purple-red pelite and pelitic siltstone. The third section of the Badong formation is located in the middle and bottom parts of the landslide and the major lithology is gray pelite, a layer of grayish-green calcareous mudstone was found in the khaki weathering surfaces.

The Huangtupo landslide is composed of four independent sliding masses, including the Biandianzhan landslide, the Yuanyichang landslide, the No. 1 slumped mass, and the No. 2 slumped mass. These masses are divided by the town of Sandaogou, whose west front lies on the No. 1 slumped mass. The Yuanyichang landslide lies on the upper part of the No. 1 slumped mass, whereas its east front lies on the No. 2 slumped mass. The Biandianzhan landslide lies on the upper part of the No. 2 slumped mass (Figure 1). Both the Biandianzhan and Yuanyichang landslides are bedding rock ones. The No. 1 and No. 2 slumped masses are located in the front part of the Huangtupo landslide which has a steep slope surface. This portion of the Huangtupo landslide suffers from frequent human activities and poor stability. The China University of Geosciences investigated the basic geological background of the disaster-prone area in the Three Gorges Reservoir; as a disaster prevention measure, a tunnel was excavated inside the No. 1 slumped mass. The tunnel was $908 \mathrm{~m}$ long and divided into five branches. Among the branches, the No. 3 branch was the longest with a length of $140 \mathrm{~m}$ (Figure 2).

The No. 1 slumped deposit is connected with the No. 2 slumped deposit along the east of the Badong Newport wharf-gas station-county hospital in west boundary and along the bedrock of Sandaogou bridge in the east boundary. The trailing edge of the No. 1 slumped deposit is covered by the Yuanyichang landslide with an elevation of $250 \mathrm{~m}$ to $290 \mathrm{~m}$, whereas its front edge reaches the Yangtze River directly with an elevation of $70 \mathrm{~m}$ to $90 \mathrm{~m}$. The slumped deposit is $770 \mathrm{~m}$ long from south to north and $450-500 \mathrm{~m}$ wide from east to west, covering an area of $32.50 \times 10^{4} \mathrm{~m}^{2}$. The slumped mass has an average thickness of $69.40 \mathrm{~m}$ and maximum thickness of $95.27 \mathrm{~m}$, covering an area of $2255.5 \times$ $10^{4} \mathrm{~m}^{3}$. The slope of the No. 1 slumped deposit is composed of loose colluviums, consisting of yellowish-gray and grayishgreen limestones, as well as cataclasites of marl. The slip bed is represented by the grayish-green limestone and marl of the second and third segments of the Badong formation in the Triassic system, respectively.

\section{Experimental Material and Testing Method}

3.1. Experimental Material. The experimental material was the original slip zone soil taken from the $138 \mathrm{~m}$ depth of the No. 3 branch in the excavated tunnel (Figure 3). The elevation 


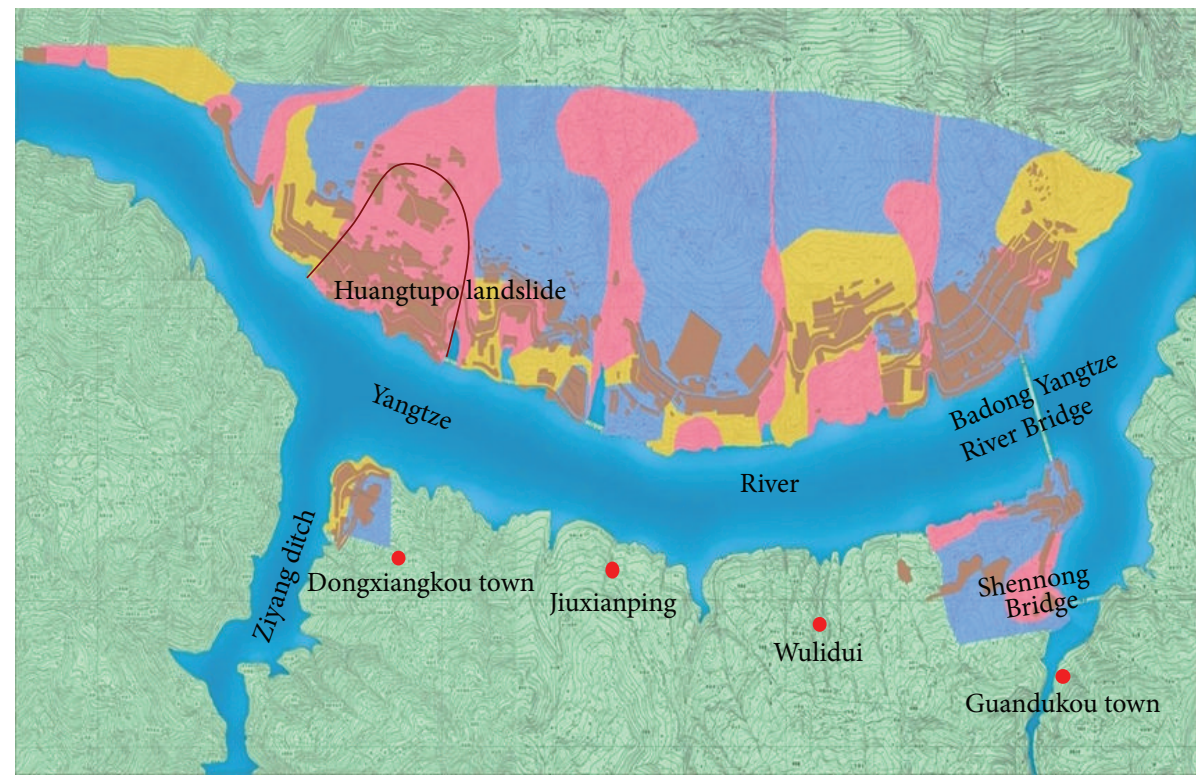

(a) Landslide location

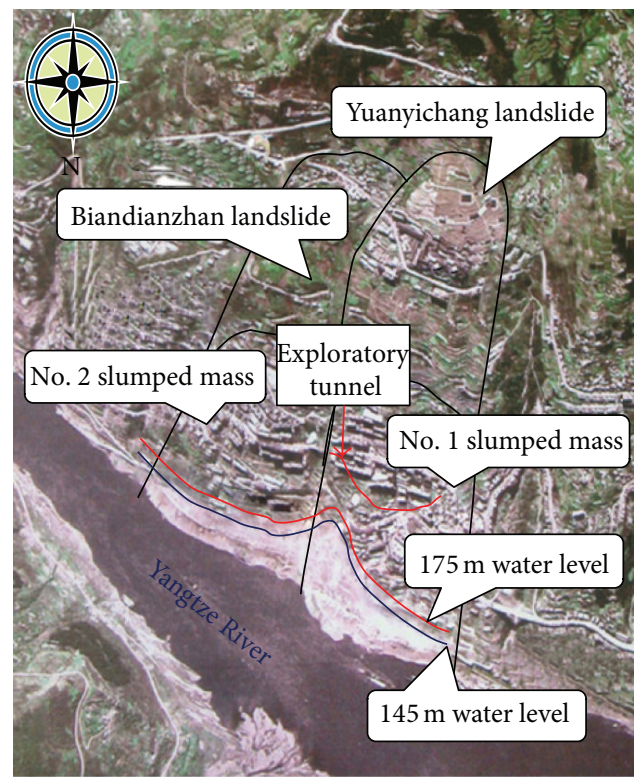

(b) Landslide structure

FIgURE 1: Huangtupo landslide.

TABLE 1: Physical properties of the slip zone soil.

\begin{tabular}{lccccc}
\hline Dry density $\left(\mathrm{g} / \mathrm{cm}^{3}\right)$ & Specific gravity & Natural water content & Liquid limit & Plastic limit & Plastic index \\
\hline 1.96 & 2.68 & $11.2 \%$ & $34.6 \%$ & $16.5 \%$ & $18.1 \%$ \\
\hline
\end{tabular}

of the No. 3 branch is about $190 \mathrm{~m}$; therefore, the variation of the reservoir water level has no influence on the testing material. The sample has a size of $350 \mathrm{~mm} \times 180 \mathrm{~mm} \times 150 \mathrm{~mm}$ and was placed in a $400 \mathrm{~mm} \times 400 \mathrm{~mm} \times 200 \mathrm{~mm}$ sampling box after being packed with two layers of plastic wrap and sealed with atoleine. The samples were stored well and little disturbance occurred during test.
The physical parameters of the slip zone soil are shown in Table 1. According to the statistical results of various groups of laboratory soil tests, for the intact slip zone soil, the specific gravity is 2.68 , the dry density is $1.96 \mathrm{~g} / \mathrm{cm}^{3}$, and the natural water content is $11.2 \%$, respectively; for the soil samples rebuilt by removing particles larger than $0.5 \mathrm{~mm}$, the liquid limit is $34.6 \%$ and the plastic limit is $16.5 \%$, respectively. 


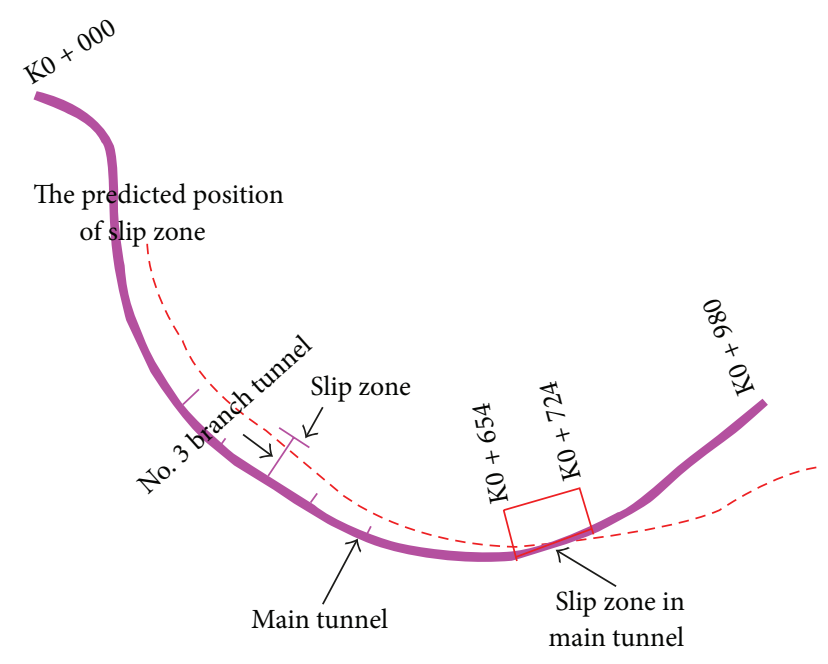

Figure 2: Schematic diagram of the exploratory tunnel in the Huangtupo landslide (plan view).

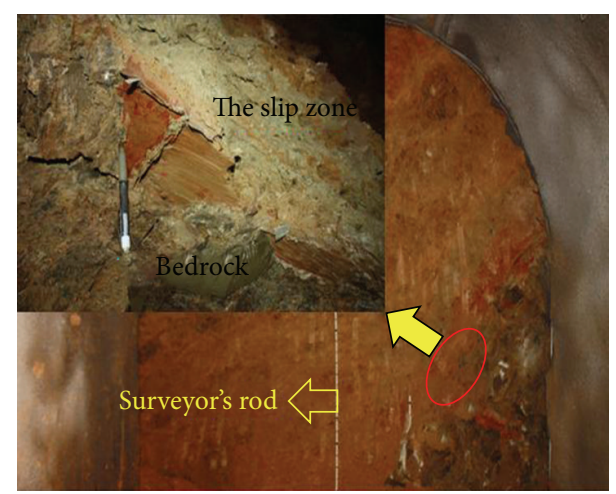

FIGURE 3: Slip zone of the Huangtupo landslide in No. 3 branch tunnel.

Figure 4 shows the grain size distribution curve obtained by using screening and densimeter methods. As can be seen, $14.5 \%$ of the slip zone soil is composed of clay. Moreover, the liquid and plastic limit and the grading curve indicate that the slip zone soil belongs to low liquid limit clay containing gravel [15].

3.2. Experimental Method and Process. In this experiment, the physical parameters were obtained through an indoor soil test, as shown in Table 1 and Figure 4 . Then, the reduction law of the strength of the slip zone soil was investigated through a wetting-drying cycle test. Based on the obtained results, the components and the variation process of physical parameters of slip zone soil under wetting-drying cycle condition were investigated using X-ray diffraction (XRD) method, as well as liquid and plastic limit test method, respectively.

3.3. Direct Shear Test under the Wetting-Drying Cycles. Regarding the indoor shear tests for rocks and soils, there have been many results for references $[6,16,17]$. Herein, we performed direct shear tests on soil specimens under

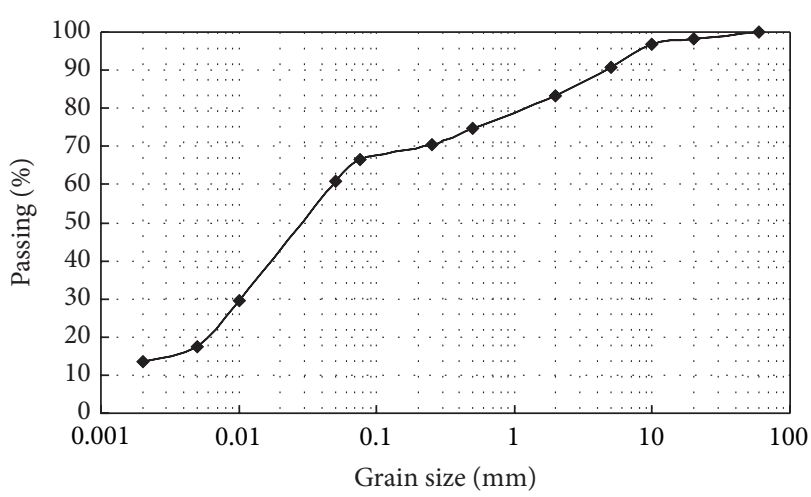

FIGURE 4: Grain size distribution curve for the slip zone soil.

repeated wetting-drying condition. A wetting-drying cycle refers to the process of the complete saturation to natural dry state. The sample preparation was to reproduce the saturated and dry states of several wetting-drying cycles. According to the particle distribution of the soil sample plotted in Figure 4, the particle size less than $2 \mathrm{~mm}$ accounts for about $85 \%$. In order to reduce the influence of size effect, the gravels larger than $2 \mathrm{~mm}$ were removed in the process of the sample preparation. The original slip zone soil is weighed and made into a cutting ring sample with height of $20 \mathrm{~mm}$ and diameter of $61.8 \mathrm{~mm}$, respectively. In a wetting-drying process, the sample is firstly vacuumized in a vacuum pump, secondly, water is injected into the vacuum pump to submerge the sample for 2-3 hours, and thirdly, the sample was soaked in water in a container for 48 hours to saturate it completely. After corresponding tests, the sample was dried for the next round of tests. It was exposed in the air for natural drying until its weight returns to the original state (at the room temperature of $25^{\circ} \mathrm{C}$ ). To ensure drying state, the sample was weighed several times until its weight did not change any longer. After returning to its original state, the sample was wrapped in plastic and put into a moist air cabinet for 48-72 hours to keep the water content constant (Figure 5). This experimental methodology has the advantages of easy operation and sample reuse.

To investigate the relationship between the shear strength and the wetting-drying cycle, a shear test for consolidated samples was conducted by using DJY-4 quadruple uniform strain direct shear apparatus (Figure 6), the loading rate was $0.8 \mathrm{~mm} / \mathrm{min}$, and the so-called consolidation was achieved through putting the sample under a heavy punch for 24 hours [15]. This test was conducted for 0 to 6 cycles, and each cycle included two groups of parallel tests by two same testing machines. Each group had four samples, and 14 groups in total were tested. After the shear tests, two of the eight samples in each cycle were taken for XRD tests, and the rest were used for liquid and plastic limit tests.

3.4. Liquid and Plastic Limit Tests. The tests aim to investigate the impact of the wetting-drying cycle on the change of soil property. The samples obtained from the direct shear tests are the ones used for the liquid and plastic limit tests. After the 


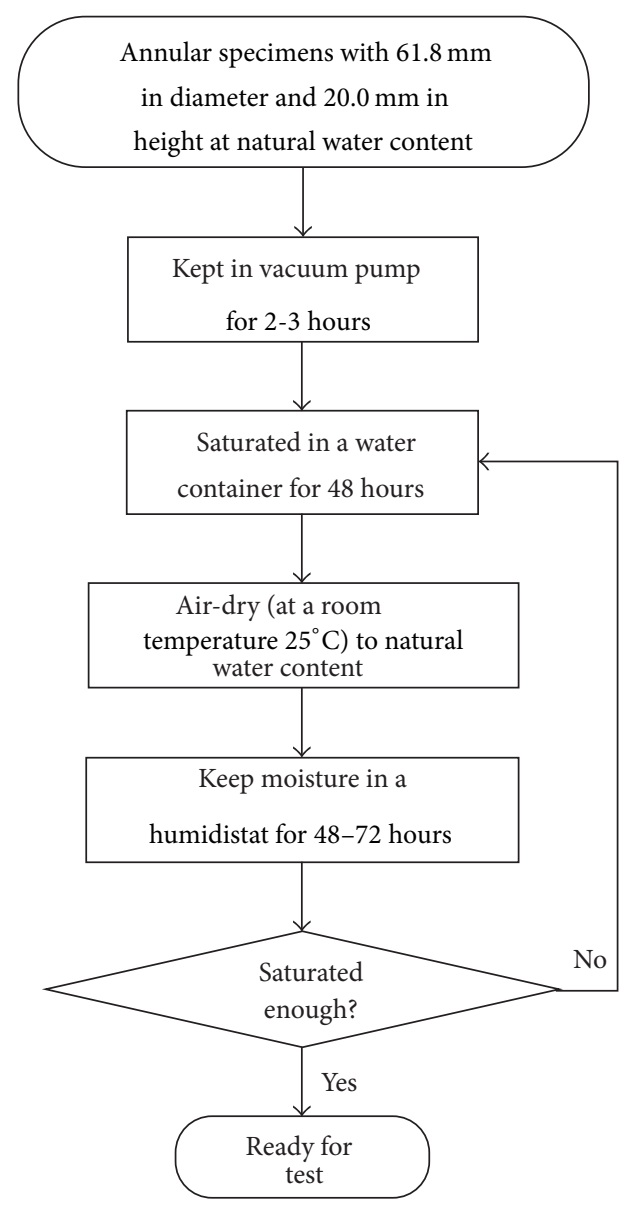

FIgURE 5: Flowchart of the wet-dry cycle.

direct shear tests, the samples were released and soaked in water in containers until they became loose. Then, screening and washing operations were performed to remove particles larger than $0.5 \mathrm{~mm}$. Finally, the remaining parts of the soils were dried and rebuilt into samples. Corresponding to the direct shear test, the liquid and plastic limit tests were also conducted for 0 to 6 cycles. The testing method defined by standard for soil test method was used to measure the liquid limit, plasticity, and plasticity index of the slip zone soils [15].

3.5. XRD Test. X-ray diffraction (XRD) test is to semiquantitatively determine the mineral components of soils through the diffraction produced by the X-ray. In this study, the XRD test was conducted on the samples obtained from the direct shear tests by using the D8 Advance X-ray diffractometer. During the test, the samples were ground to powder. The diffraction patterns were obtained after the XRD tests, which took the diffraction angle of $2 \theta$ as the $x$-coordinate and the diffracted intensity of diffraction spectral line (height of the diffraction peak) as the $y$-coordinate. However, interplanar crystal spacing $d$ and diffracted intensity were also used to identify minerals. The diffracted intensity can be obtained through the diffraction patterns. The interplanar crystal spacing can be expressed as follows: $d=\lambda / 2 \sin \theta$, where $\lambda$ is the wavelength of the $\mathrm{X}$-ray and $\theta$ is the diffraction angle. Finally, we compared the diffraction patterns obtained by XRD tests with the standard diffraction patterns of known minerals; different mineral contents can be accordingly quantified (Figure 7).

\section{Test Results and Discussions}

4.1. Direct Shear Strength. Based on the strength envelope line under different cyclic conditions (Figure 8), the slip zone soils became weak after the first cycle and the strength values reached relatively stable states after four cycles. However, the relatively stable values of the slip zone soils are smaller than their initial values. Figure 9 shows the impact of the wettingdrying cycle on the strength parameters of the slip zone soil. As can be seen, two strength parameters of the slip zone soils, namely, cohesion $\mathbf{c}$ and friction angle $\varphi$, initially decreased and then increased with increasing number of cycles. The strength parameter $\mathrm{c}$ showed maximum reduction after the first cycle and gradually reached a relatively stable value after four cycles, decreasing by approximately $14.7 \%$ compared to its initial value. Similarly, for the strength parameter $\varphi$, maximum reduction after the first cycle was observed and gradually a relatively stable state was reached after four cycles. The reason for the soil behaviors observed above might be due to the water-soluble and hydrophilic mineral contents. Upon the first appearance of the water, physical and chemical changes occur, and the strength values decrease accordingly. With some soluble components going into the water, the soil strength parameters reach relatively stable values. The deep mechanism of these phenomena needs to be further uncovered. According to statistics [18], approximately 50\% of reservoir landslides occurred during the first impounding, whereas most of the rest landslides occurred within three to five years after impounding [4]. These results are consistent with the test results of the current study. Maximum decrease in strength of the slip zone soils after the first wetting-drying cycle was observed, indicating that the reservoir bank slope loses stability in the early stage of impoundment. The strength values generally stabilized after four cycles, but generally the stabilized values were smaller than the initial values. The results show that the safety factor of the bank slope decreases and the slope loses stability gradually upon the first impoundment and after several cycles of water level fluctuation.

4.2. Liquid and Plastic Limit Tests. The results of the liquid and plastic limit tests for the slip zone soils under different wetting-drying cycles are shown in Table 2 and Figure 10. As can be seen, there was a significant increase of the liquid limits of the slip zone soils after the first cycle and then the gradual decrease was observed with the increasing number of the cycles. Correspondingly, the plasticity index of the slip zone soils had a maximum increase after the first cycle and then stabilized gradually. The reason for the observed variation of the soil indices is similar to soil strength parameters. Due to the water-soluble and hydrophilic mineral contents, physical and chemical changes may occur under the participation of 


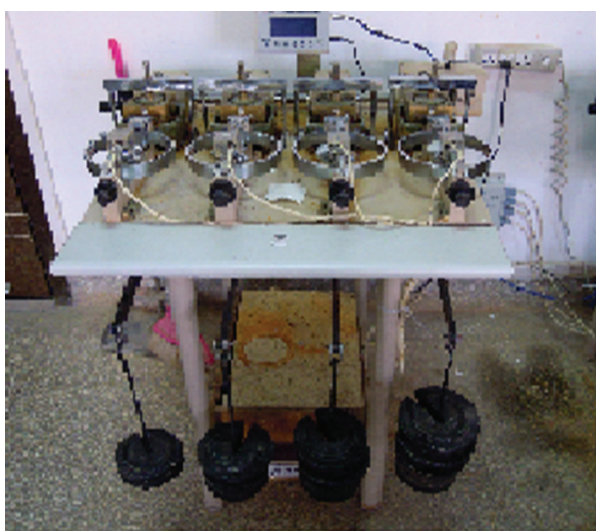

(a) Testing apparatus

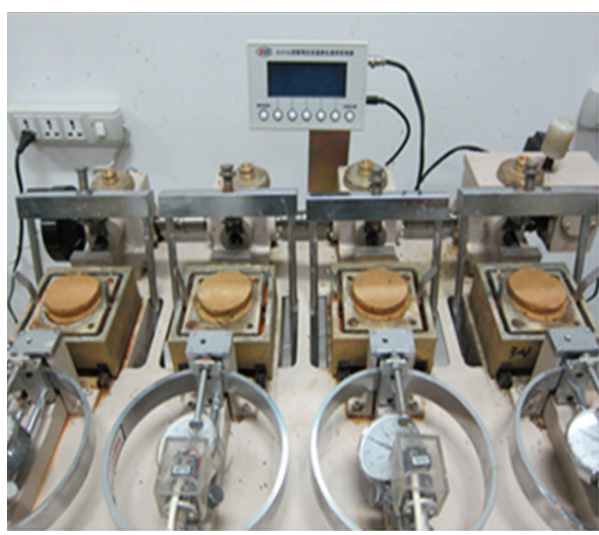

(c) End of the test

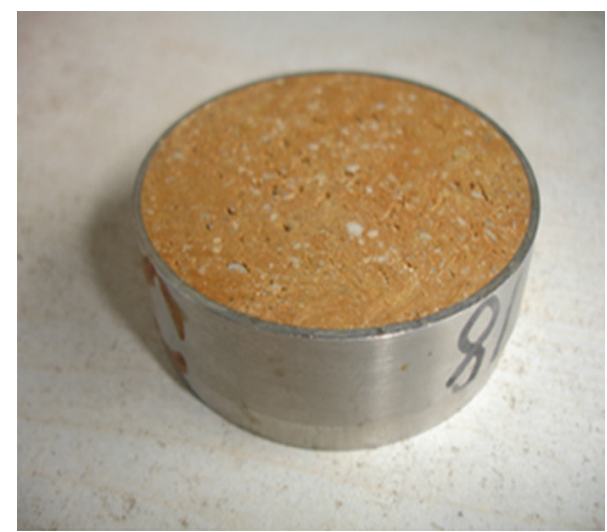

(b) Annular specimen with diameter of $61.8 \mathrm{~mm}$ and height of $20.0 \mathrm{~mm}$

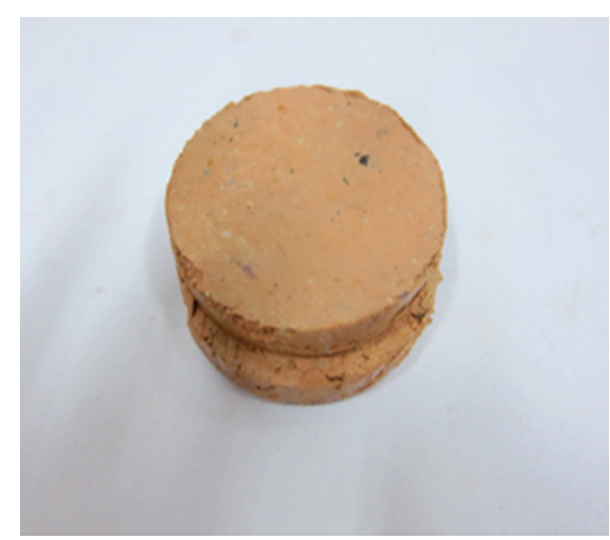

(d) The destructed sample

Figure 6: Direct shear test.

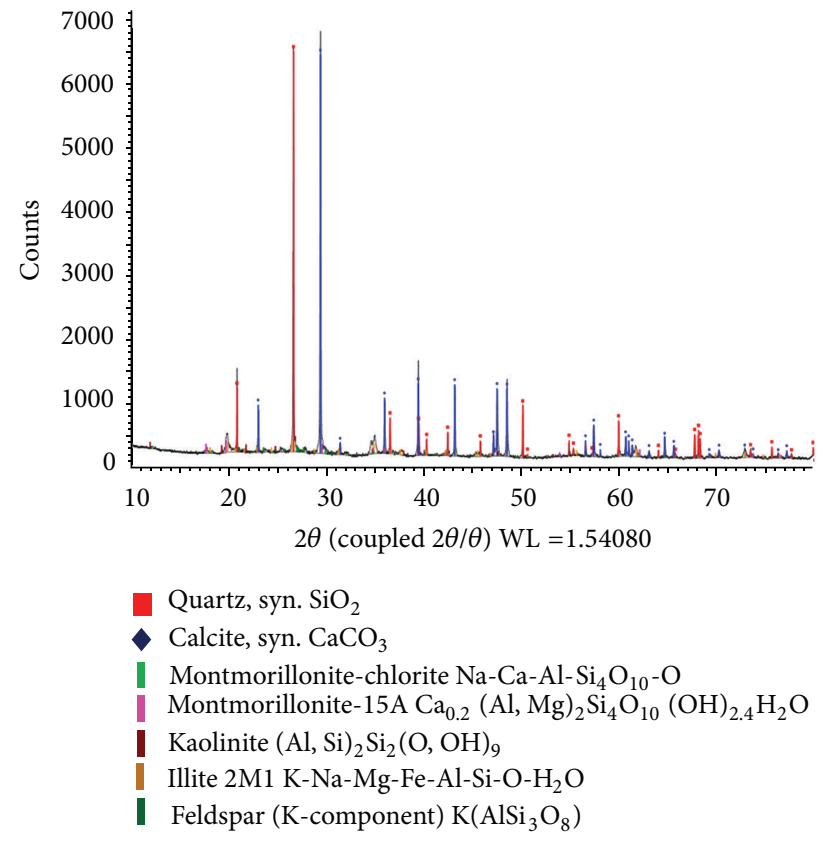

(a) Diffraction pattern of the sample after six cycles

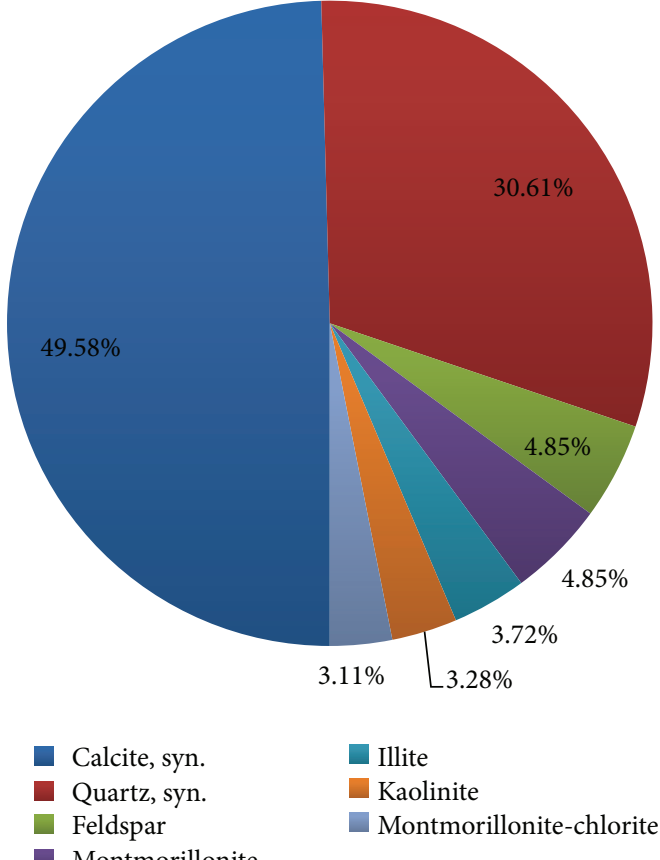

(b) Schematic diagram of processing results

FIgURe 7: XRD test. 


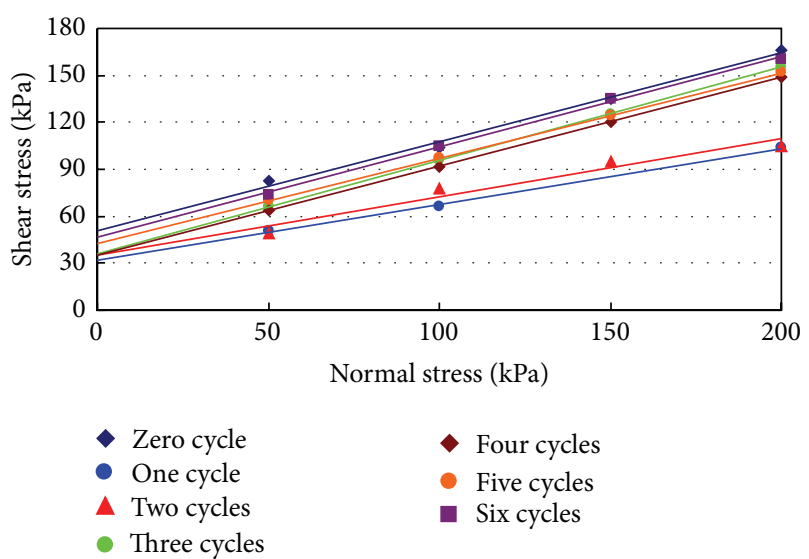

FIGURE 8: The strength envelope of the slip zone soil under different numbers of cycle.

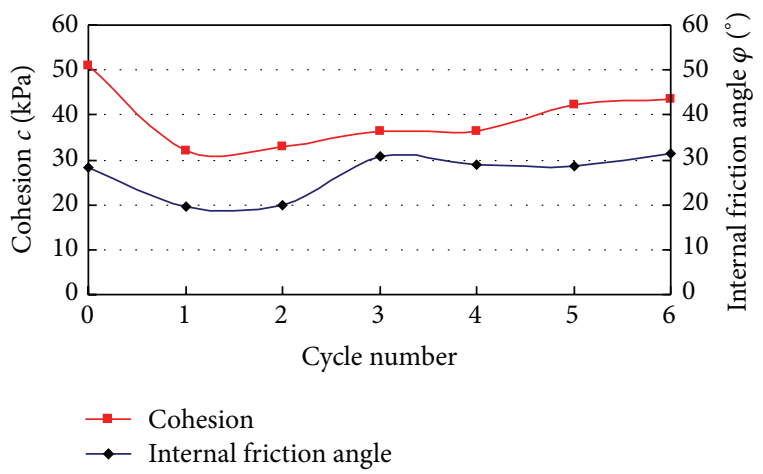

FIGURE 9: Relationship between the shearing strength parameters and cyclic number.

TABLE 2: Results of the liquid and plastic limits under different wetdry cycles.

\begin{tabular}{lccc}
\hline Cycle & Plastic limit (\%) & Liquid limit (\%) & Plastic index \\
\hline 0 & 17.15 & 33.78 & 16.63 \\
1 & 15.88 & 36.95 & 21.07 \\
2 & 15.70 & 34.50 & 18.80 \\
3 & 15.70 & 34.10 & 18.40 \\
4 & 15.95 & 34.20 & 18.25 \\
5 & 16.64 & 33.90 & 17.26 \\
6 & 16.80 & 34.00 & 17.20 \\
\hline
\end{tabular}

water, and changes in liquid and plastic indices may take place corresponding to the mineral contents in the soils. The liquid limits and plastic limits are important physical characteristic indices that reflect the impact of water on the soil properties. Therefore, the plasticity index can be used for engineering soil classification. The liquid limit, the plastic limit, and the plasticity index of soils vary depending on the wetting-drying cycle. The plasticity index of the slip zone soils increased by $27.1 \%$ from its initial value of $16.6-21.1 \%$ after the first cycle, indicating that the wetting-drying cycles can significantly change the properties of the slip zone soils.

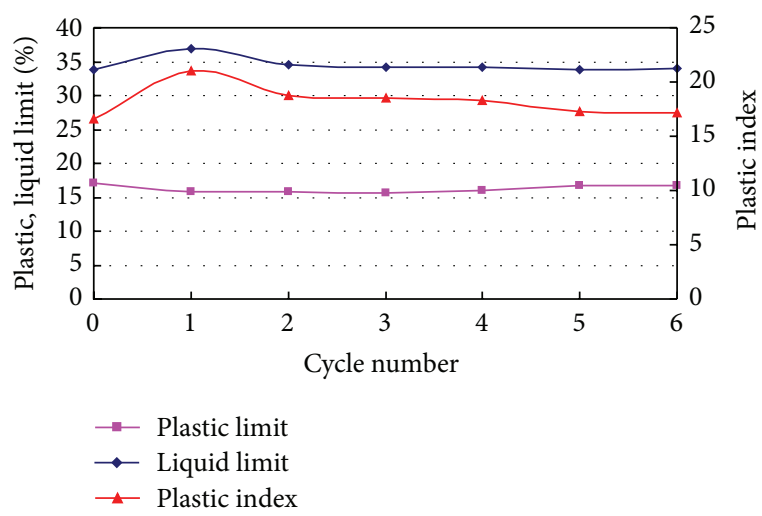

FIgURE 10: Variations in the plastic, liquid limit, and plastic index with cycle number.

4.3. XRD Test Results. As summarized in Table 3 and Figure 11, the results of the XRD tests show that the main minerals in the slip zone soils include quartz and calcite which occupy $30 \%$ and $50 \%$ of the soil, respectively. The clay minerals include illite, montmorillonite, kaolin, and montmorillonite-chlorite-mixture; they occupy $9.98 \%$ of the soil in total. The content of clay minerals in the slip zone soil gradually increased with the increase of cycle number; $15 \%$ of increment was found after six cycles. Among the clay minerals, the contents of montmorillonite and kaolin relatively increased, particularly after the first cycle, whereas the content of the illite remained constant. On the other hand, the contents of calcite and quartz in the slip zone soils slightly decreased. The above mentioned phenomenon may be due to the fact that an amount of hydrophilic and water-soluble minerals exist in the soils, and upon the appearance of water, physical and chemical changes take place, and some of the minerals went away with the water during the soaking of the samples; resultantly, alteration in mineral contents occurs.

The results of the direct shear tests and the liquid and plastic limit tests demonstrate that the variation of strength parameter $\varphi$ of the slip zone soil exhibited a trend opposite to that of the plasticity index with cycle variation. The plasticity index had a maximum increase, whereas the strength parameter $\varphi$ had a maximum decrease after the first cycle. From the second cycle, the plasticity index gradually decreased and became stable relatively, whereas $\varphi$ gradually increased and became stable relatively, indicating that the increase of the plasticity index of the slip zone soils leads to the decrease of their strength during the wetting-drying cycles. These results agree well with the results of Tiwari and Ajmera [19], who observed that the strength parameter $\varphi$ of the slip zone soil decreased with increasing plasticity index.

The slip zone soils of landslides are mostly composed of montmorillonite, illite, chlorite, kaolinite, talc, sericite, graphite, gypsum, and other minerals. A slip zone soil with such components often possesses low mechanical strength and small internal friction angle. Particularly, the strength of a slip zone soil significantly decreases after being soaked in water. Wen and Chen [20] proposed that quartz will be hydrolyzed and form a kaolinite mineral when the slip zone 


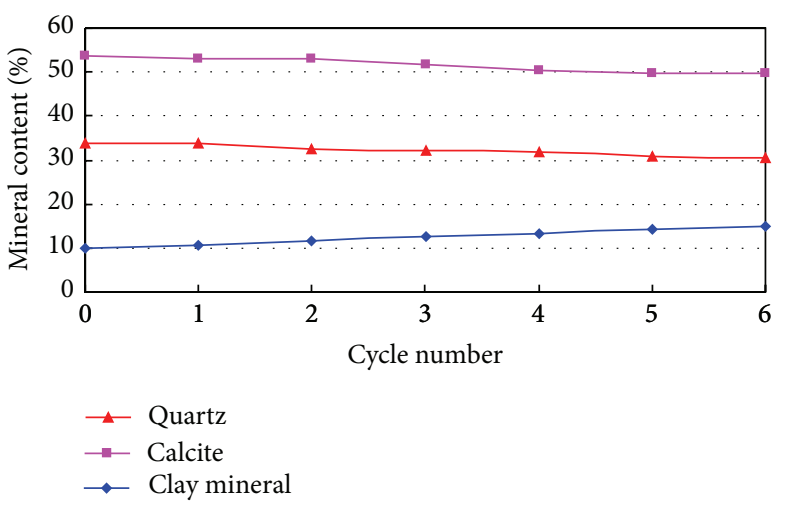

(a) Variations in quartz, calcite, and the total clay mineral content

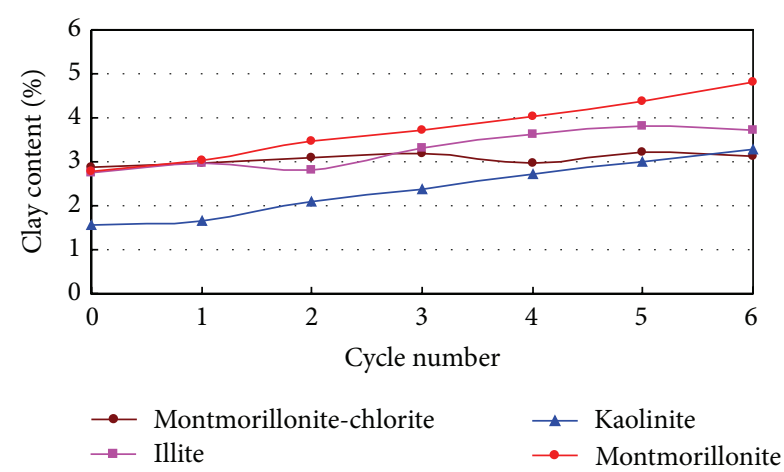

(b) Variations in the four kinds of clay minerals

FIgURE 11: Variation in mineral content under the wet-dry cycle.

TABLE 3: Results of the XRD tests under different wet-dry cycles.

\begin{tabular}{|c|c|c|c|c|c|c|c|}
\hline \multirow{2}{*}{ Cycles } & \multicolumn{7}{|c|}{ Minerals and their relative content (\%) } \\
\hline & Feldspar & Quartz & Calcite & Montmorillonite-chlorite & Illite & Kaolinite & Montmorillonite \\
\hline 0 & 2.36 & 33.92 & 53.74 & 2.88 & 2.76 & 1.56 & 2.78 \\
\hline 1 & 2.61 & 33.7 & 53.06 & 2.97 & 2.98 & 1.66 & 3.02 \\
\hline 2 & 3.12 & 32.56 & 52.88 & 3.1 & 2.8 & 2.08 & 3.46 \\
\hline 3 & 3.79 & 32.04 & 51.58 & 3.2 & 3.32 & 2.36 & 3.71 \\
\hline 4 & 4.57 & 31.66 & 50.37 & 2.98 & 3.64 & 2.73 & 4.03 \\
\hline 5 & 4.66 & 30.97 & 49.76 & 3.23 & 3.82 & 2.99 & 4.37 \\
\hline 6 & 4.85 & 30.62 & 49.57 & 3.11 & 3.72 & 3.28 & 4.82 \\
\hline
\end{tabular}

soil is soaked in enclosed underground water for a long time. The increasing of clay mineral content in the slip zone is the main reason for the decrease in shear strength. Shuzui [21] stated that, with the presence of the underground water, the calcite dissolves and produces montmorillonite and other clay minerals, and resultantly, the strength of the slip zone soil decreases significantly. In this context, the change of the clay mineral content in the slip zone soils plays an important role in the evolution of landslide disasters.

However, the results of the direct shear tests and XRD tests show that the clay mineral content in the slip zone soil increases gradually with the increasing number of wettingdrying cycles. Moreover, the strength of a slip zone soil increases at first and then decreases until reaching a relatively stable value. These results seem to contradict the idea that the shear strength of a soil decreases with the increasing clay mineral content. Many scholars have investigated the strength of the slip zone soil through probing into the microstructure of the sliding zones, and they believed that the variation in the sequence of particles influences the strength of the slip zone soil [22-24]. Alonso et al. [25] introduced the elastic-plastic constitutive model of swelling soil under the wetting-drying cycles based on an experimental study and divided the soil deformation into micro- and macroscopic one; it was found that the microstructural variation under the wetting-drying cycles affects the connections among particles; thus, bigger pore spaces can be formed in the soil mass [25]. Therefore, the microstructural variation during the wetting-drying cycles may be another reason for the decrease in the strength of the slip zone soil.

\section{Conclusions}

Taking the Huangtupo landslide in the Three Gorges Reservoir as an example, this experimental study investigated the strength reduction, the physical property variation, and the component variation of the slip zone soils under the wettingdrying cycles. The results demonstrate that the shear strength of the slip zone soils varied with the wetting-drying cycles; the strength and cycle numbers can be fitted using certain functions. With the increasing time of wetting-drying cycles, the strength of the slip zone soils significantly decreases and then gradually increases and then reaches a relatively stable value. However, the relatively stable strength value is smaller than the initial one. The plasticity index variation and the increased clay content under the wetting-drying cycles lead to the decrease of the slip zone soil strength; in particular, the strength reduction of a slip zone soil is negatively correlated with the plasticity index variation. However, with increasing number of wetting-drying cycles, the clay mineral content in a slip zone soil increases gradually, and the strength of the slip zone soil decreases at first and then increases until it reaches a stabile value. The results reveal that other factors, such as the microstructure of the slip zone soils and the wettingdrying cycle conditions, can also result in the reduction of the slip zone soil strength. It should be noted that, for the first 
time, we went into the slip zone of an ancient landslide in the Three Gorges Reservoir and sampled soils on site; through systematic indoor experiments, we obtained a number of first-hand insights of the landslide evolution in that area. This study can provide basic information for the failure mechanism of the landslide disasters of reservoir banks.

\section{Conflict of Interests}

The authors declare that there is no conflict of interests regarding the publication of this paper.

\section{Acknowledgments}

This study was financially supported by the National Basic Research Program of China (973 Program) (2011CB710602), the Key Research Program of the Chinese Academy of Sciences (KZZD-EW-05-03), and the China National Natural Science Foundation (40972201). The anonymous reviewers who presented constructive comments for this paper are specially appreciated.

\section{References}

[1] J. G. Liu, P. J. Mason, N. Clerici et al., "Landslide hazard assessment in the Three Gorges area of the Yangtze river using ASTER imagery: Zigui-Badong," Geomorphology, vol. 61, no. 1-2, pp. 171-187, 2004.

[2] F. W. Wang, Y. M. Zhang, Z. T. Huo, T. Matsumoto, and B. L. Huang, "The July 14, 2003 Qianjiangping landslide, Three Gorges Reservoir, China," Landslides, vol. 1, no. 2, pp. 157-162, 2004.

[3] H. Yin and C. Li, "Human impact on floods and flood disasters on the Yangtze River," Geomorphology, vol. 41, no. 2-3, pp. 105109, 2001.

[4] X. Hu, H. Tang, C. Li, and R. Sun, "Stability of Huangtupo riverside slumping mass II\# under water level fluctuation of Three Gorges Reservoir," Journal of Earth Science, vol. 23, no. 3, pp. 326-334, 2012.

[5] Y. Y. Jiao, Z. H. Wang, X. Z. Wang, A. C. Adoko, and Z. X. Yang, "Stability assessment of an ancient landslide crossed by two coal mine tunnels," Engineering Geology, vol. 159, pp. 36-44, 2013.

[6] I. Gratchev and I. Towhata, "Geotechnical characteristics of volcanic soil from seismically induced Aratozawa landslide, Japan," Landslides, vol. 7, no. 4, pp. 503-510, 2010.

[7] Q. L. Deng, Z. Y. Zhu, Z. Q. Cui, and X. P. Wang, "Mass rock creep and landsliding on the Huangtupo slope in the reservoir area of the Three Gorges Project, Yangtze River, China," Engineering Geology, vol. 58, no. 1, pp. 67-83, 2000.

[8] H. B. Wang, W. Y. Xu, R. C. Xu, Q. H. Jiang, and J. H. Liu, "Hazard assessment by 3D stability analysis of landslides due to reservoir impounding," Landslides, vol. 4, no. 4, pp. 381-388, 2007.

[9] J. Jiang, D. Ehret, W. Xiang et al., "Numerical simulation of Qiaotou Landslide deformation caused by drawdown of the Three Gorges Reservoir, China," Environmental Earth Sciences, vol. 62, no. 2, pp. 411-419, 2011.

[10] Y. M. Hong and S. Wan, "Forecasting groundwater level fluctuations for rainfall-induced landslide," Natural Hazards, vol. 57, no. 2, pp. 167-184, 2011.
[11] G. W. Jia, T. L. T. Zhan, Y. M. Chen, and D. G. Fredlund, "Performance of a large-scale slope model subjected to rising and lowering water levels," Engineering Geology, vol. 106, no. 1-2, pp. 92-103, 2009.

[12] Z. Yan, J. Wang, and H. Chai, "Influence of water level fluctuation on phreatic line in silty soil model slope," Engineering Geology, vol. 113, no. 1-4, pp. 90-98, 2010.

[13] C. Tang, "Numerical simulation of progressive rock failure and associated seismicity," International Journal Of Rock Mechanics And Mining Sciences \& Geomechanics Abstracts, vol. 34, no. 2, pp. 249-261, 1997.

[14] Y. Jiao, X. Zhang, and J. Zhao, “Two-dimensional DDA contact constitutive model for simulating rock fragmentation," Journal of Engineering Mechanics, vol. 138, no. 2, pp. 199-209, 2012.

[15] The Ministry of Water Resources of the PRC, Standard for Soil Test Method (GB/T50123-1999), Standard Press of China, Beijing, China, 1999.

[16] H. Fukuoka, K. Sassa, and G. Wang, "Influence of shear speed and normal stress on the shear behavior and shear zone structure of granular materials in naturally drained ring shear tests," Landslides, vol. 4, no. 1, pp. 63-74, 2007.

[17] S. B. Vithana, S. Nakamura, S. Gibo, A. Yoshinaga, and S. Kimura, "Correlation of large displacement drained shear strength of landslide soils measured by direct shear and ring shear devices," Landslides, vol. 9, no. 3, pp. 305-314, 2012.

[18] R. Cojean and Y. J. Caï, "Analysis and modeling of slope stability in the Three-Gorges Dam reservoir (China) - the case of Huangtupo landslide," Journal of Mountain Science, vol. 8, no. 2, pp. 166-175, 2011.

[19] B. Tiwari and B. Ajmera, "A new correlation relating the shear strength of reconstituted soil to the proportions of clay minerals and plasticity characteristics," Applied Clay Science, vol. 53, no. 1, pp. 48-57, 2011.

[20] B. P. Wen and H. Y. Chen, "Mineral compositions and elements concentrations as indicators for the role of groundwater in the development of landslide slip zones: a case study of large-scale landslides in the Three Gorges Area in China," Earth Science Frontiers, vol. 14, no. 6, pp. 98-106, 2007.

[21] H. Shuzui, "Process of slip-surface development and formation of slip-surface clay in landslides in Tertiary volcanic rocks, Japan," Engineering Geology, vol. 61, no. 4, pp. 199-219, 2001.

[22] K. R. Early and A. W. Skempton, "Investigations of the landslide at Walton's Wood, Staffordshire," Quarterly Journal of Engineering Geology, vol. 5, no. 1-2, pp. 19-41, 1972.

[23] R. W. W. Anson and A. B. Hawkins, "Analysis of a sample containing a shear surface from a recent landslip, south Cotswolds, UK," Geotechnique, vol. 49, no. 1, pp. 33-41, 1999.

[24] J. F. Lupini, A. E. Skinner, and P. R. Vaughan, "Drained residual strength of cohesive soils," Geotechnique, vol. 31, no. 2, pp. 181213, 1981.

[25] E. E. Alonso, E. Romero, C. Hoffmann, and E. García-Escudero, "Expansive bentonite-sand mixtures in cyclic controlledsuction drying and wetting," Engineering Geology, vol. 81, no. 3, pp. 213-226, 2005. 

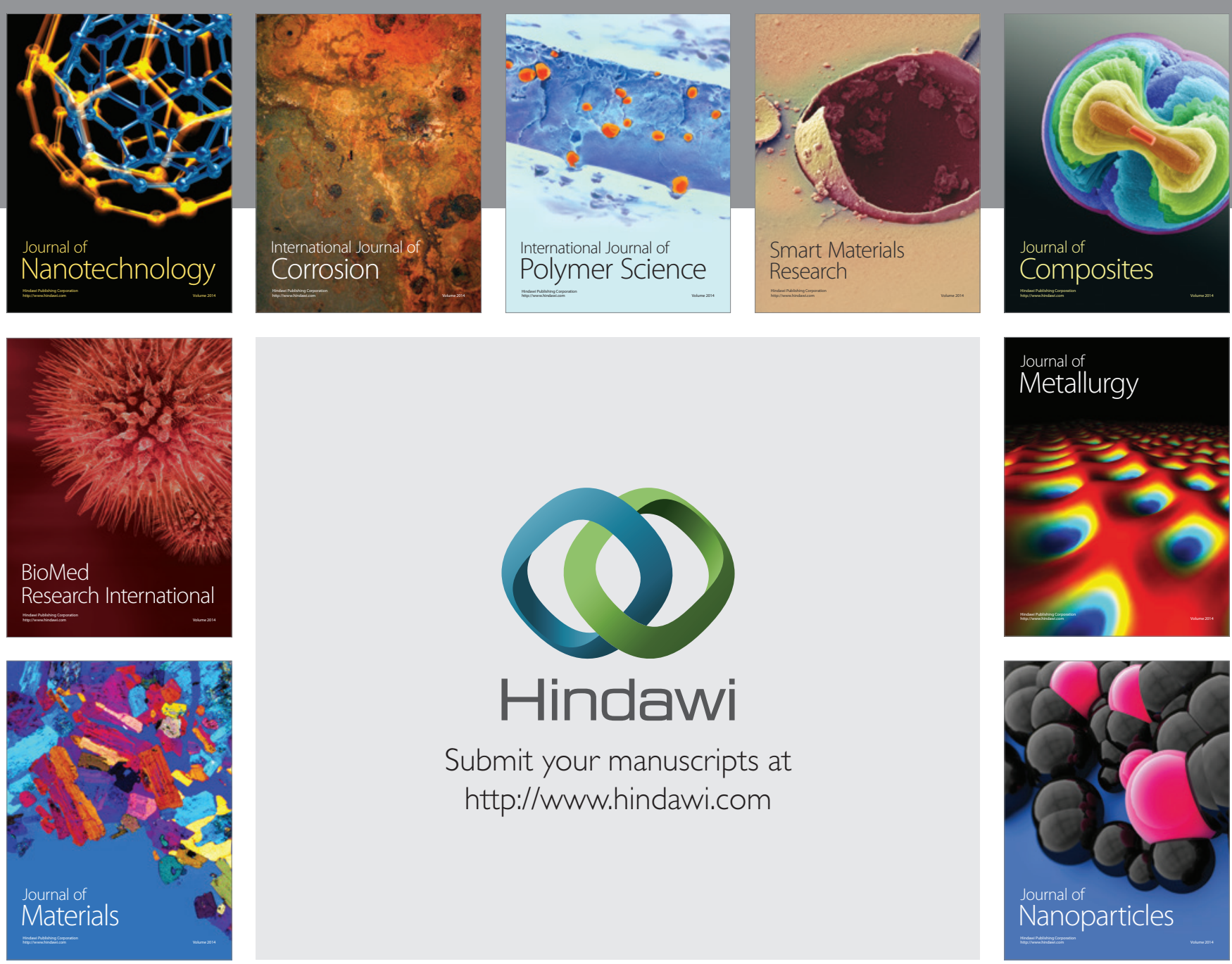

Submit your manuscripts at http://www.hindawi.com
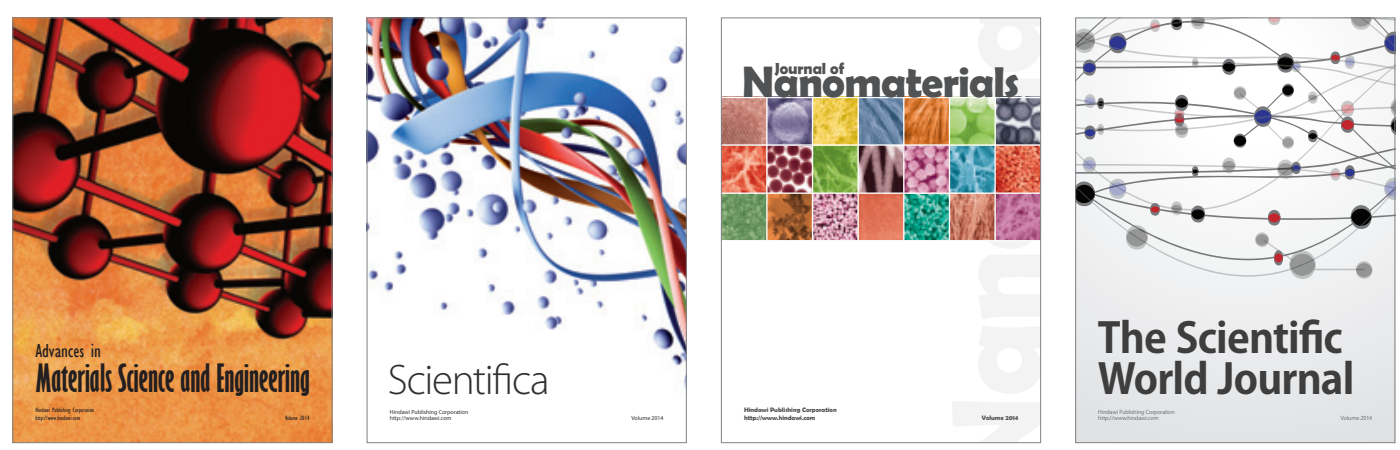

\section{The Scientific World Journal}
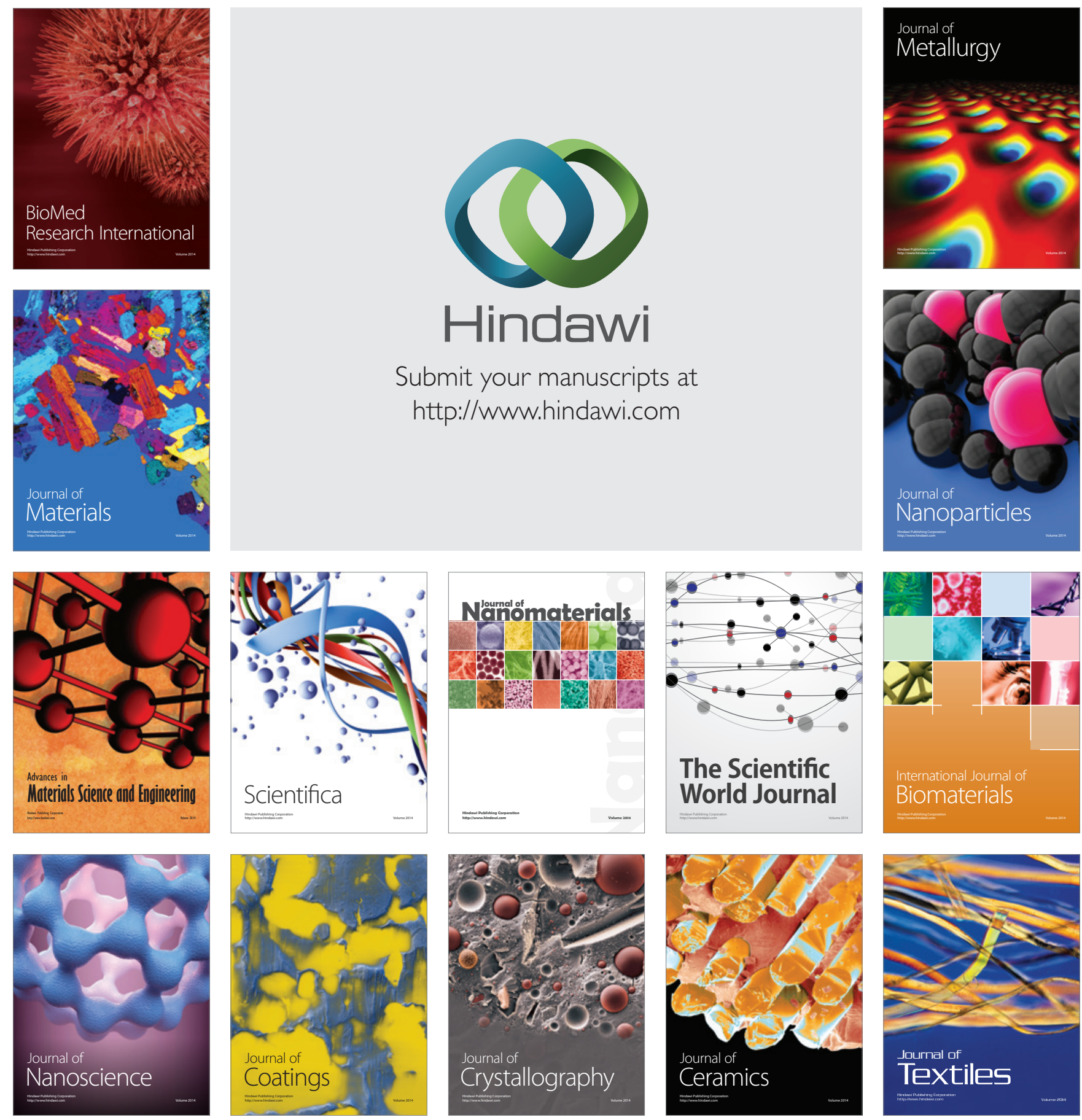